\title{
ANALISIS ALIRAN DAYA UNTUK PENENTUAN LOKASI PENYALURAN DAYA PLTN PADA SISTEM KALIMANTAN BARAT
}

\author{
Citra Candranurani, Rizki Firmansyah Setya Budi, Sahala M. Lumbanraja \\ Pusat Kajian Sistem Energi Nuklir (PKSEN BATAN), \\ Jl. Kuningan Barat, Mampang Prapatan, Jakarta 12710 \\ Email: citra@batan.go.id
}

\begin{tabular}{|c|c|c|}
\hline Diterima & Diterima dalam bentuk revisi & Disetujui \\
\hline 10 Februari 2015 & 14 April 2015 & 28 April 2015 \\
\hline
\end{tabular}

\begin{abstract}
ABSTRAK
ANALISIS ALIRAN DAYA UNTUK PENENTUAN LOKASI PENYALURAN DAYA PLTN PADA SISTEM KALIMANTAN BARAT. Kondisi kelistrikan di Kalimantan Barat (Kalbar) diketahui dalam situasi krisis akibat jumlah kapasitas daya pembangkit yang hampir sama dengan beban puncak. Sistem tidak memiliki cadangan pembangkitan sehingga mengakibatkan defisit listrik ketika ada pembangkit yang tidak beroperasi. Kebijakan perencanaan listrik hingga tahun 2022 adalah membangun PLTU untuk mengganti PLTD yang telah ada. Untuk perencanaan jangka panjang diperlukan peranan energi baru terbarukan guna mengurangi ketergantungan pemakaian bahan bakar fosil, diantaranya adalah pemanfaatan PLTN. Tujuan penelitian adalah untuk mengetahui lokasi optimum penyaluran daya PLTN dalam rangka persiapan infrastruktur kelistrikan. Metode perhitungan aliran daya menggunakan perangkat lunak ETAP 12.5. Perencanaan pengoperasian PLTN digunakan untuk memikul beban dasar, agar optimum dengan faktor kapasitas diatas 80\%. Hasil penelitian menunjukkan 3 lokasi optimum yang dapat membangkitkan daya diatas 80\%, yaitu: GI Mempawah, GI Singkawang, dan GI Sambas. Lokasi paling optimum berada di GI Mempawah dengan faktor kapasitas 83,5\%. Letak ketiga GI ini sejalan dengan salah satu syarat untuk pembangunan PLTN, yaitu tersedianya sumber air pendingin karena lokasi tersebut di pinggir pantai.
\end{abstract}

Kata kunci: aliran daya, lokasi optimum, PLTN, Kalimantan Barat

\begin{abstract}
LOAD FLOW ANALYSIS FOR DETERMINING THE LOCATION OF NPP POWER DISTRIBUTION IN WEST KALIMANTAN. Electricity crisis condition happened in West Kalimantan (Kalbar) as a result of power plant capacity almost equal to the peak load. The system will experience a shortfall if there are plants that not operating and do not have reserve. The policy of electricity planning until 2022 is replacing diesel power plant with steam power plant. For long-term planning is required the role of new and renewable energi in order to reduce dependency on fossil fuel consumption, such as NPP utilization. The purpose of this study was to determine the optimum location of the NPP power distribution in order to prepare electricity infrastructure. Load flow calculation in this study using ETAP 12.5 software. NPP is planned to supply base load, so the optimum capacity factor is above $80 \%$. The result show that there are three location where NPP can generate over $80 \%$ of its capacity, namely: Mempawah Substation, Singkawang Substation, and Sambas Substation. The most optimum located in Mempawah Substation with capacity factor 83.5\%. The location of the three Substation are onshore and in line with one requirement for NPP construction, namely: the availability of cooling water.
\end{abstract}

Keywords: load flow, optimum location, NPP, West Kalimantan 


\section{PENDAHULUAN}

Keandalan ketersediaan energi listrik di wilayah Kalimantan Barat saat ini dalam kondisi kritis. Daya mampu sistem dan beban puncak memiliki nilai yang hampir sama sehingga sistem tidak memiliki cadangan pembangkitan (reserve margin). Akibatnya sistem akan mengalami kekurangan pasokan apabila ada jadwal perawatan pembangkit. Guna memenuhi kebutuhan listrik, PT. PLN (Persero) merencanakan pembelian listrik dari Sarawak di tahun 2015-2019 sebesar 50-230 MW[1]. Untuk mengurangi ketergantungan dengan negara lain, perlu direncanakan sistem kelistrikan di Kalbar yang mandiri dan andal[1,2].

Berdasarkan ketersediaan energi primer dan mempertimbangkan kebijakan pemanfaatan energi untuk mendukung keberlanjutan penyediaan energi, pada tahun 2031 direncanakan akan di masukkan opsi nuklir ke dalam sistem kelistrikan Kalbar sebesar 100 $\mathrm{MW}^{[3]}$. Hal ini sesuai dengan kebijakan pemerintah tentang target bauran energi yang tertuang dalam Perpres No. 5 tahun 2006 yang mentargetkan pasokan energi nuklir sebesar $2 \%$ dari total kebutuhan energi nasional di tahun 2025[4].

Perencanaan pemanfaatan Pembangkit Listrik Tenaga Nuklir (PLTN) di Kalbar, memerlukan persiapan diantaranya dalam sistem kelistrikan. Tujuan penelitian ini adalah untuk mengetahui lokasi penyaluran daya keluaran PLTN yang tepat ke dalam sistem kelistrikan Kalbar. Metodologi yang digunakan adalah dengan melakukan studi aliran daya di sistem Kalbar dengan bantuan perangkat lunak ETAP 12,5. Pentingnya penelitian adalah untuk menciptakan keseimbangan ketersediaan pembangkit dengan kebutuhan beban ${ }^{[5]}$. Dalam studi aliran daya, terdapat 3 tahapan proses yaitu menghitung perkiraan beban, kebutuhan pembangkit, dan perencanaan kebutuhan transmisi ${ }^{[6,7]}$.

\section{METODOLOGI}

\subsection{Dasar Teori dan Tahapan Penelitian}

Studi aliran daya adalah metode analisis sinusoidal yang menggunakan persamaan aljabar non linier yang digunakan untuk mengetahui nilai dari tegangan, sudut daya, daya aktif dan reaktif di suatu bus ${ }^{[8,9]}$. Kegunaan studi ini dapat memberikan acuan untuk operasi harian agar tidak terjadi pembebanan berlebih di peralatan ${ }^{[10]}$. Ada 3 metode dasar yang umum digunakan dalam perhitungan aliran daya, yaitu: Gauss-Seidal, Newton Raphson, Decoupled dan Fast Decoupled[9]. Berdasarkan kelebihan dan kekurangan, maka metode Newton Raphson adalah metode terbaik dan banyak digunakan ${ }^{[11,12]}$.

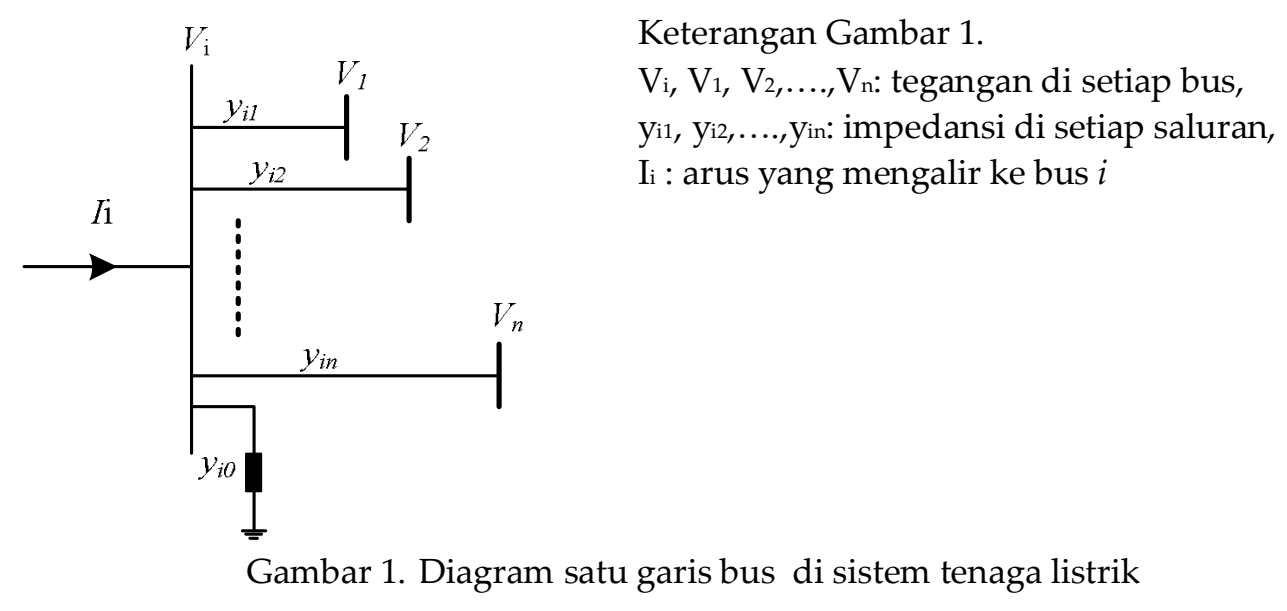


Persamaan daya pada bus i adalah ${ }^{[13]}$ :

$$
P_{i}+j Q_{i}=V_{i} I_{i}^{*}
$$

Keterangan:

tanda $(*)$ adalah konjuget

$\mathrm{Pi}=$ daya aktif di bus $\mathrm{i}$,

$\mathrm{Qi}=$ daya reaktif di bus $\mathrm{i}$

sehingga diperoleh persamaan:

$$
I_{i}=\frac{P_{i}-j Q_{i}}{V_{i}^{*}}
$$

Untuk setiap y saluran transmisi, arus pada setiap bus adalah:

$$
I_{i}=V_{i} \sum_{j=0}^{n} y_{i j}-\sum_{j=i}^{n} y_{i j} V_{j} \text { dengan } j \neq i
$$

dengan mensubstitusi persamaan (1) ke persamaan (2) diperoleh:

$$
\frac{P_{i}-j Q_{i}}{V_{i}^{*}}=V_{i} \sum_{j=0}^{n} y_{i j}-\sum_{j=i}^{n} y_{i j} V_{j} \operatorname{dengan~} j \neq i
$$

dalam bentuk matriks admitansi, persamaan (2) dapat ditulis menjadi:

$$
I_{i}=\sum_{j=i}^{n} Y_{i j} V_{j} V_{i}
$$

atau dalam bentuk polar menjadi:

$$
I_{i}=\sum_{j=1}^{n}\left|Y_{i j} V_{j} V_{i}\right| \angle\left(\theta_{i j}+\delta_{j}\right)
$$

Daya kompleks di bus i adalah:

$$
\mathrm{P}_{\mathrm{i}}-\mathrm{j} \mathrm{Q}_{\mathrm{i}}=\mathrm{V}_{\mathrm{i}} \angle \delta_{\mathrm{i}} \sum_{\mathrm{j}=1}^{\mathrm{n}}\left|\mathrm{Y}_{\mathrm{ij}} \mathrm{V}_{\mathrm{j}}\right| \angle\left(\theta_{\mathrm{ij}}+\delta_{\mathrm{j}}\right)
$$

Daya aktif di bus i adalah:

$$
P_{i}=\sum_{j=1}^{n}\left|Y_{i j} V_{j} V_{i}\right| \cos \left(\theta_{i j}+\delta_{j}-\delta_{i}\right)
$$

Daya reaktif di bus i adalah:

$$
\mathrm{Q}_{\mathrm{i}}=-\sum_{\mathrm{j}=1}^{\mathrm{n}}\left|\mathrm{Y}_{\mathrm{ij}} \mathrm{V}_{\mathrm{j}} \mathrm{V}_{\mathrm{i}}\right| \sin \left(\theta_{\mathrm{ij}}+\delta_{\mathrm{j}}-\delta_{\mathrm{i}}\right)
$$

Perhitungan aliran daya dalam studi ini menggunakan bantuan perangkat lunak ETAP 12.5 (Electrical Transient Analyzer Program). Setiap bus yang menjadi acuan dalam studi ini adalah gardu induk (GI) $150 \mathrm{kV}$ dan $275 \mathrm{kV}$. Hasil perhitungan daya aktif di setiap GI adalah sama dengan daya aktif di setiap bus. Termasuk daya aktif yang dibangkitkan oleh setiap pembangkit yang ada dalam sistem Kalbar.

Tahapan pelaksanaan penelitin dapat dilihat pada Gambar 2. Tahap awal adalah mengumpulkan data sistem Kalbar yang eksisting, data yang dikumpulkan meliputi pembangkit, transmisi, transformator dan beban. Keseluruhan data dimasukkan ke dalam perangkat lunak ETAP 12.5. Tahap selanjutnya adalah menghitung proyeksi beban dan kebutuhan transformator dari tahun 2023 hingga 2031. Hasil perhitungan data tersebut dimasukkan ke dalam ETAP 12.5. Tahap akhir dari penelitian adalah menentukan lokasi 
PLTN yang akan dihubungkan ke dalam sistem Kalbar dengan hasil penyaluran daya yang paling optimum berdasarkan daya keluaran PLTN.

\subsection{Sistem Kelistrikan Kalimantan Barat}

Saat ini sistem kelistrikan Kalbar terdiri dari satu sistem interkoneksi 150 kV yang disebut dengan sistem khatulistiwa, beberapa sistem yang terisolasi (isolated system), dan wilayah khusus yang listriknya bersumber dari Serawak-Malaysia. Sistem khatulistiwa mencakup wilayah Pontianak hingga Singkawang dengan beban penyaluran puncak terbesar, yaitu 223,1 MW dan terdapat sekitar total $67 \%$ produksi listrik untuk Kalbar. Sistem isolated terdiri atas sistem Sambas, Bengkayang, Ngabang, Ketapang, Sanggau, Sekadau, Putusibau, Sintang, dan Nanga Pinoh ${ }^{[1]}$. Beban puncak pada sistem interkoneksi di tahun 2012 adalah 335 MW. Rencana untuk mengambil alih beban pada sistem isolated untuk dihubungkan ke dalam sistem interkoneksi $150 \mathrm{kV}$, maka pada tahun 2022 beban puncak di Kalbar menjadi $951 \mathrm{MW}$ atau laju pertumbuhan rata-rata $11 \%$ per tahun ${ }^{[1]}$.

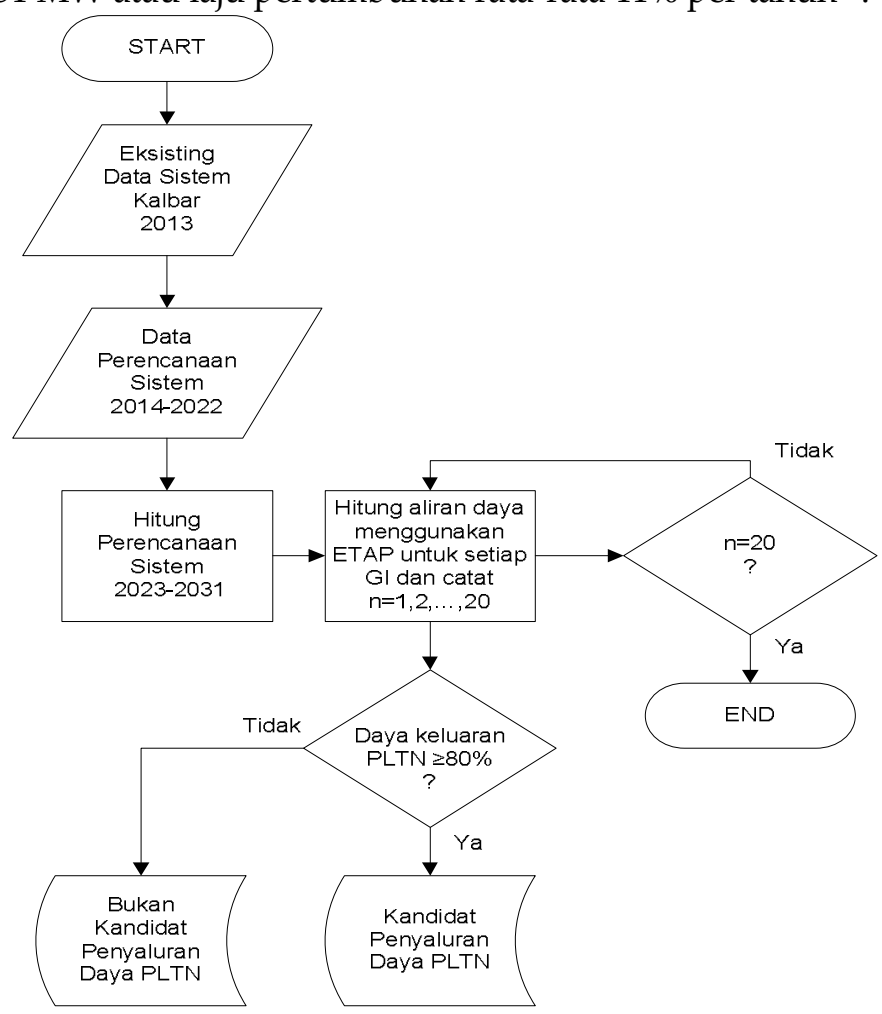

Gambar 2. Diagram Alir Metodologi Penelitian

Tabel 1. Perencanaan sistem kelistrikan Kalbar tahun 2013-2022 ${ }^{[1]}$

\begin{tabular}{lccccc}
\hline No. & Tahun & $\begin{array}{r}\text { Beban Puncak } \\
(\mathrm{MW})\end{array}$ & $\begin{array}{c}\text { Pembangkit } \\
(\mathrm{MW})\end{array}$ & $\begin{array}{c}\text { Transmisi } \\
(\mathrm{kms})\end{array}$ & $\begin{array}{c}\text { Transformator } \\
(\mathrm{MVA})\end{array}$ \\
\hline 1. & 2013 & 371 & 6 & 166 & 120 \\
2. & 2014 & 402 & 14 & 304 & 210 \\
3. & 2015 & 457 & 176 & 212 & 120 \\
4. & 2016 & 512 & 163 & 750 & 150 \\
5. & 2017 & 569 & 100 & 1160 & 150 \\
6. & 2018 & 632 & 100 & 180 & 180 \\
7. & 2019 & 701 & 100 & - & 60 \\
8. & 2020 & 777 & 200 & - & - \\
9. & 2021 & 860 & 200 & - & -
\end{tabular}




\begin{tabular}{cccccc}
\hline No. & Tahun & $\begin{array}{c}\text { Beban Puncak } \\
(\mathrm{MW})\end{array}$ & $\begin{array}{c}\text { Pembangkit } \\
(\mathrm{MW})\end{array}$ & $\begin{array}{c}\text { Transmisi } \\
(\mathrm{kms})\end{array}$ & $\begin{array}{c}\text { Transformator } \\
(\mathrm{MVA})\end{array}$ \\
\hline 10. & 2022 & 951 & 48 & - & - \\
\hline
\end{tabular}

Perencanaan pengembangan pembangkit di Kalbar hingga tahun 2022 sebagian besar adalah pembangunan pembangkit listrik tenaga uap (PLTU) berbahan bakar batubara untuk menggantikan pembangkit listrik tenaga diesel (PLTD) dengan biaya produksi tinggi. Selain itu, ada rencana pembelian listrik dari Sarawak di tahun 2015-2019 untuk memenuhi kebutuhan base load sebesar 50 MW dan beban puncak sebesar hingga 230 MW. Pada Tabel 1 ditunjukkan perencanaan sistem kelistrikan Kalbar dari tahun 2013 hingga 2022.

Untuk data perencanaan pertumbuhan pembangkit dari tahun 2023 hingga 2031 berdasarkan ketersediaan energi primer di Kalbar diketahui kandidat dan kapasitas pembangkit yang akan direncanakan adalah sebesar 800 MW[14]. Dari Tabel 2 dapat diketahui bahwa ada beberapa kandidat pembangkit yang berasal dari energi baru terbarukan seperti pembangkit biomass, CBM dan PLTN.

Tabel 2. Perencanaan Penambahan Pembangkit Listrik Tahun 2023-2031[14]

\begin{tabular}{lrcc}
\hline No. & Tahun & \multicolumn{2}{c}{ Pembangkit } \\
\cline { 3 - 4 } & & Jenis & Kapasitas (MW) \\
\hline 1. & 2023 & CCGAS & 100 \\
& & Biomass & 50 \\
& & Biomass & 50 \\
2. & 2024 & PLTG & 35 \\
& & PLTG & 35 \\
3. & 2025 & Hydro & 40 \\
4. & 2026 & CBM & 50 \\
5. & 2027 & PLTU & 100 \\
6. & 2028 & PLTU & 100 \\
7. & 2029 & Hydro & 40 \\
8. & 2030 & PLTU & 100 \\
9. & 2031 & PLTN & 100 \\
\hline
\end{tabular}

\section{HASIL DAN PEMBAHASAN}

Lokasi penyaluran daya PLTN ke dalam sistem kelistrikan Kalbar yang paling optimum dapat diketahui menggunakan studi aliran daya dengan melihat daya keluaran PLTN yang paling maksimum ${ }^{[15]}$. Perencanaan sistem Kalbar hingga tahun 2031 untuk mengetahui kondisi sistem pada tahun pengoperasian PLTN. Proyeksi beban dibuat dari data tahun 2022 dengan pertumbuhan sebesar 11\% per tahun ${ }^{[2]}$. Hingga tahun 2031, beban puncak sistem sebesar 2335 MW. Guna memenuhi kebutuhan tersebut, maka dihitung kebutuhan transformator di setiap GI dengan total tambahan 3120 MVA. Tabel 3 ditunjukkan proyeksi kebutuhan beban dan transformator tahun 2021-2031.

Pertumbuhan beban yang meningkat setiap tahun mengakibatkan adanya penambahan pembangkit dalam rangka menjaga keandalan sistem kelistrikan Kalbar. PLTN direncanakan akan beroperasi tahun 2031 dengan kapasitas 100 MW. Penentuan letak PLTN sangat berpengaruh terhadap aliran daya sistem kelistrikan Kalbar dan optimalisasi penggunaan PLTN. PLTN dinyatakan optimum jika dapat membangkitkan daya yang dibutuhkan sistem sebesar mungkin sesuai dengan kapasitasnya. Jumlah total GI pada sistem Kalbar hingga tahun 2022 adalah 20 lokasi, selanjutnyaseluruh GI ini akan digunakan dalam penelitian. 
Tabel 3. Proyeksi kebutuhan beban dan transformator untuk tahun 2021-2031

\begin{tabular}{llccc}
\hline No. & Tahun & $\begin{array}{c}\text { Beban Puncak } \\
(\mathrm{MW})\end{array}$ & $\begin{array}{c}\text { Pembangkit } \\
(\mathrm{MW})\end{array}$ & $\begin{array}{c}\text { Transformator } \\
(\mathrm{MVA})\end{array}$ \\
\hline 1. & 2021 & 860 & - & 960 \\
2. & 2022 & 951 & - & 1320 \\
3. & 2023 & 1094 & 200 & - \\
4. & 2024 & 1203 & 70 & - \\
5. & 2025 & 1322 & 40 & 120 \\
6. & 2026 & 1454 & 50 & - \\
7. & 2027 & 1598 & 100 & 60 \\
8. & 2028 & 1757 & 100 & 60 \\
9. & 2029 & 1932 & 40 & - \\
10. & 2030 & 2124 & 100 & 480 \\
11. & 2031 & 2335 & 100 & 120 \\
\hline
\end{tabular}

Berdasarkan penelitian yang telah dilakukan diperoleh beberapa lokasi penempatan PLTN. Pada Tabel 4 ditunjukkan lokasi penempatan PLTN untuk dapat terhubung ke dalam sistem kelistrikan Kalbar. Penelitian sebelumnya menyatakan bahwa unit pembangkit pemikul beban dasar dioperasikan dengan faktor kapasitas tinggi (75\%-100\%) dan PLTN termasuk ke dalam pembangkit pemikul beban dasar ${ }^{[16-19]}$. PLTN merupakan pembangkit yang memiliki indeks kegagalan dan dapat beroperasi dalam jangka waktu lama, sehingga PLTN dinyatakan optimum jika faktor kapasitasnya diatas $80 \%[20-22]$. Berdasarkan hal tersebut, dapat diketahui bahwa terdapat 3 lokasi untuk PLTN dapat membangkitkan daya diatas $80 \%$ kapasitasnya, yaitu: di GI Mempawah, GI Singkawang, dan GI Sambas. Lokasi paling optimum berada pada GI Mempawah dengan faktor kapasitas sebesar 83,5\%.

Tabel 4. Lokasi Penempatan PLTN

\begin{tabular}{rlc}
\hline No. & Gardu Induk & Daya keluaran PLTN (MW) \\
\hline 1 & Siantan & 78,4 \\
2 & Sei Raya & 76,5 \\
3 & Parit Baru & 78,8 \\
4 & Mempawah & $\mathbf{8 3 , 5}$ \\
5 & Singkawang & $\mathbf{8 1 , 5}$ \\
6 & Kota Baru & $\mathbf{7 5 , 3}$ \\
7 & PLTU Kura-kura & $\mathbf{7 6 , 9}$ \\
8 & Sambas & $\mathbf{8 2 , 6}$ \\
9 & Sanggau & 55,9 \\
10 & Tayan & 45,9 \\
11 & Bengkayang & 60,1 \\
12 & Ngabang & 49,6 \\
13 & Sekadau & 51,1 \\
14 & Sintang & 53,2 \\
15 & Nanga Pinoh & 45,1 \\
16 & Ketapang & 57,8 \\
\hline
\end{tabular}




\begin{tabular}{clc}
\hline No. & Gardu Induk & Daya keluaran PLTN (MW) \\
\hline 17 & Sandai & 54,3 \\
18 & Kota Baru 2 & 40,3 \\
19 & Sukadana & 55,3 \\
20 & Putusibau & 48 \\
\hline
\end{tabular}

Pada Gambar 3 ditunjukkan aliran daya pada tahun 2031 sebelum PLTN beroperasi. Sistem kelistrikan Kalbar membutuhkan impor listrik sebesar 80 MW. Kondisi aliran daya dan jumlah impor listrik dari Sesco akan berubah dengan beroperasinya PLTN. Besarnya perubahan aliran daya sangat dipengaruhi oleh parameter saluran dan parameter pembangkit seperti: induktansi, impedansi, kapasitas saluran, daya yang disalurkan, dan kelembaman pembangkit[23-25].

Sedang pada Gambar 4 ditunjukkan aliran daya Kalbar tahun 2031 setelah daya PLTN disalurkan melalui GI Mempawah. Penyaluran daya PLTN melalui GI Mempawah menyebabkan impor SESCO turun menjadi 73, 8 MW. GI Mempawah yang sebelumnya membutuhkan suplai daya dari GI lain menjadi surplus daya dengan adanya penyambungan daya PLTN dan memasok daya ke GI lainnya.

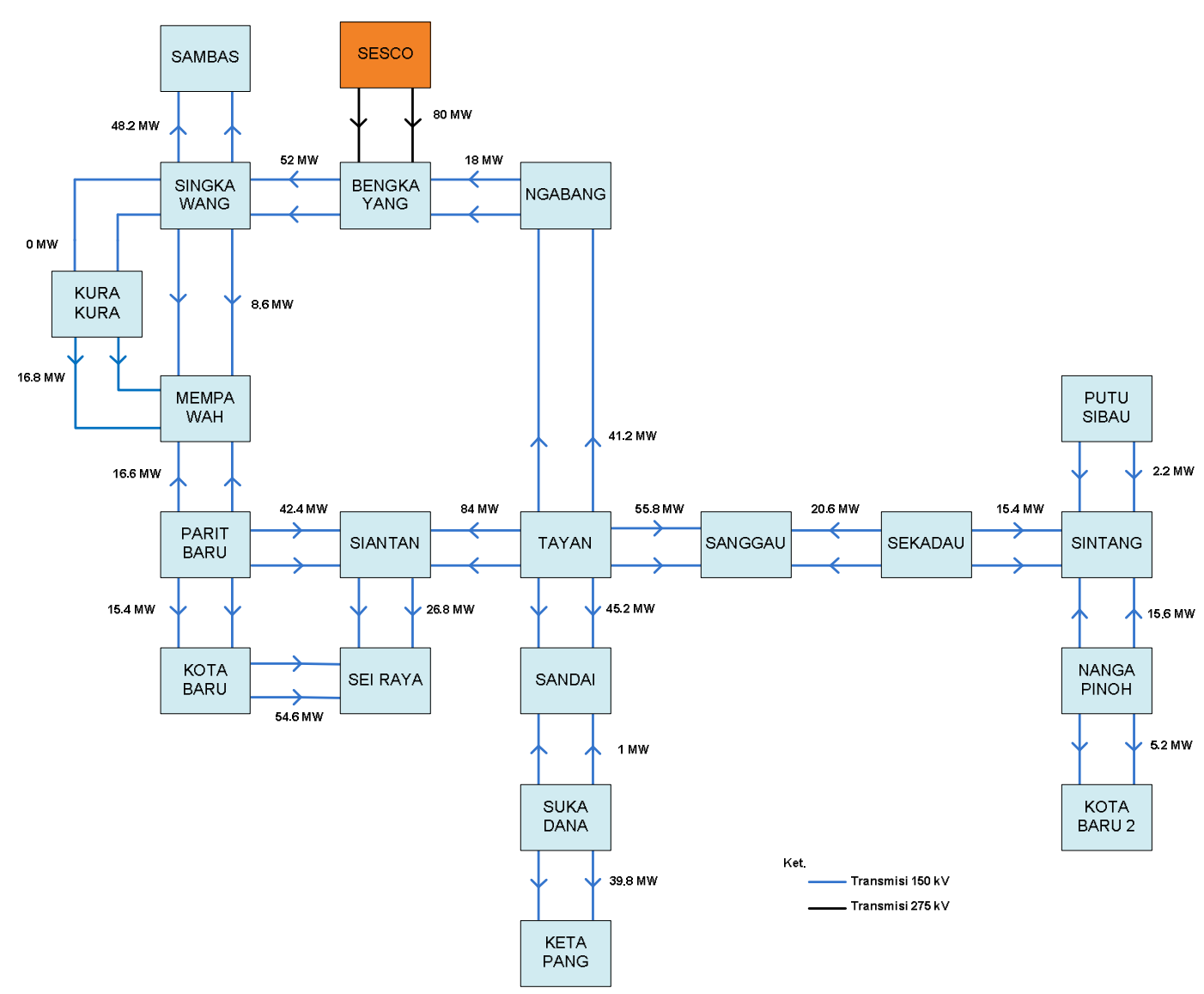

Gambar 3. Aliran daya Kalbar tahun 2031 sebelum PLTN beroperasi 


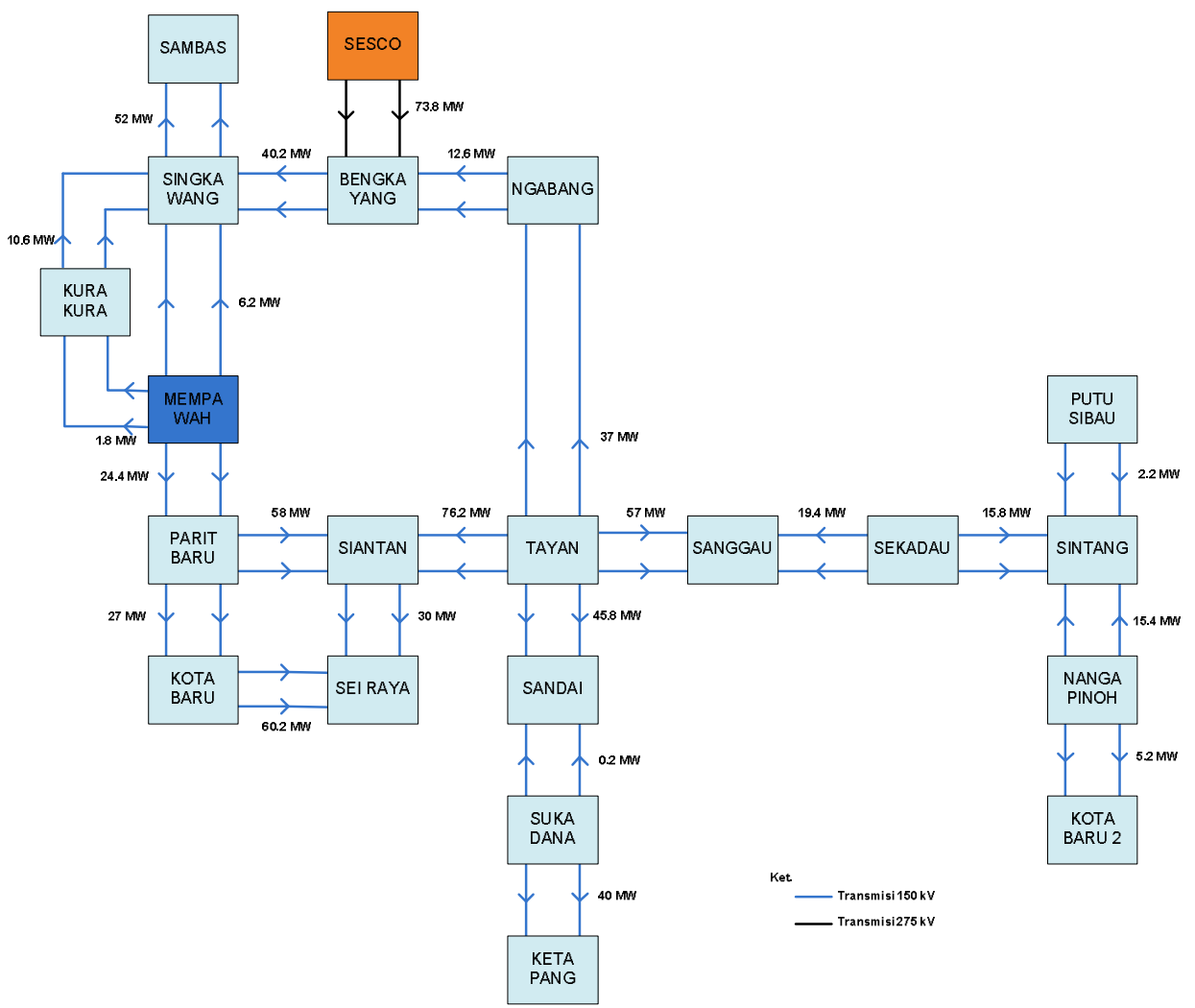

Gambar 4. Aliran daya Kalbar tahun 2031 setelah daya PLTN disalurkan melalui GI Mempawah.

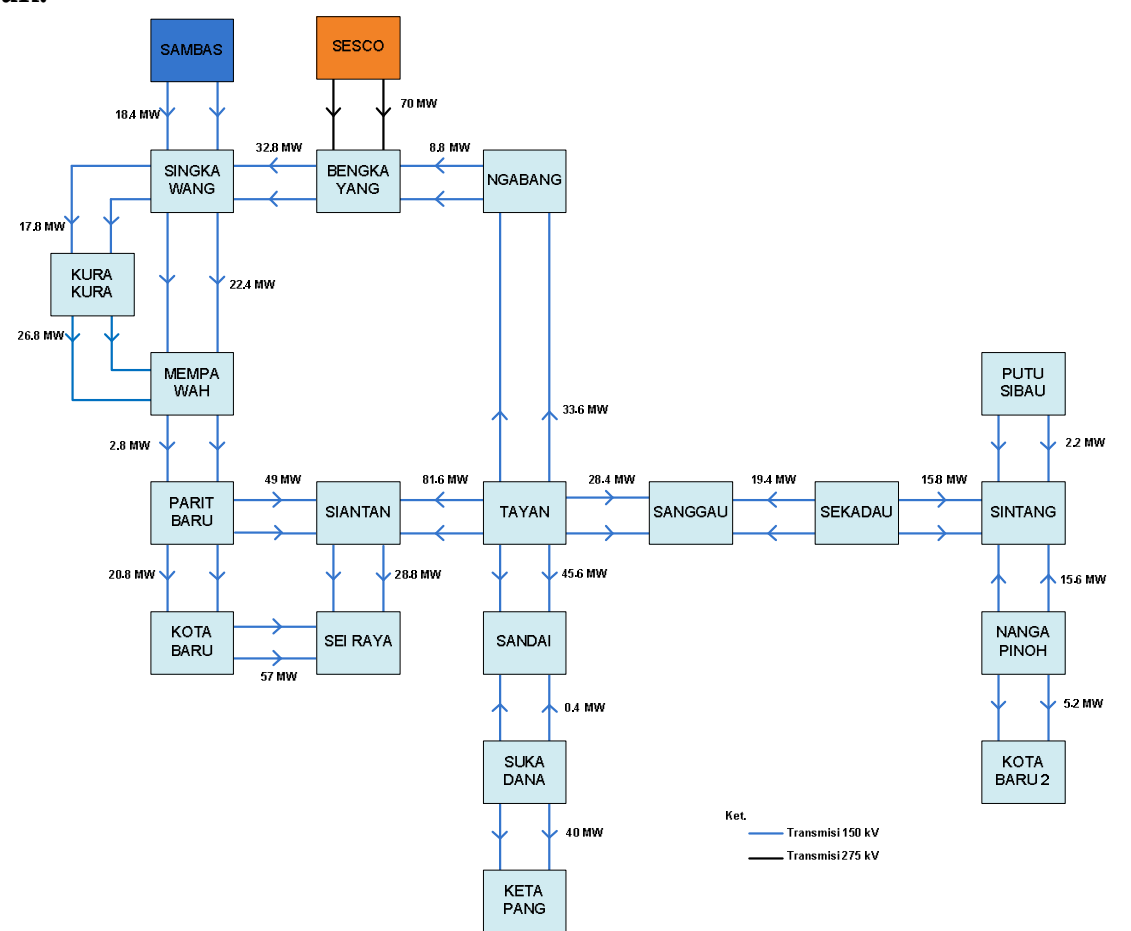

Gambar 5. Aliran daya Kalbar tahun 2031 setelah daya PLTN disalurkan melalui GI Sambas.

Pada Gambar 5 ditunjukkan aliran daya Kalbar tahun 2031 setelah daya PLTN disalurkan melalui GI Sambas. Penyaluran daya PLTN melalui GI Sambas menyebabkan 
impor SESCO turun menjadi 70 MW. GI Sambas yang sebelumnya membutuhkan suplai daya dari GI lain menjadi surplus daya dengan adanya penyambungan daya PLTN dan memasok daya ke GI lainnya.

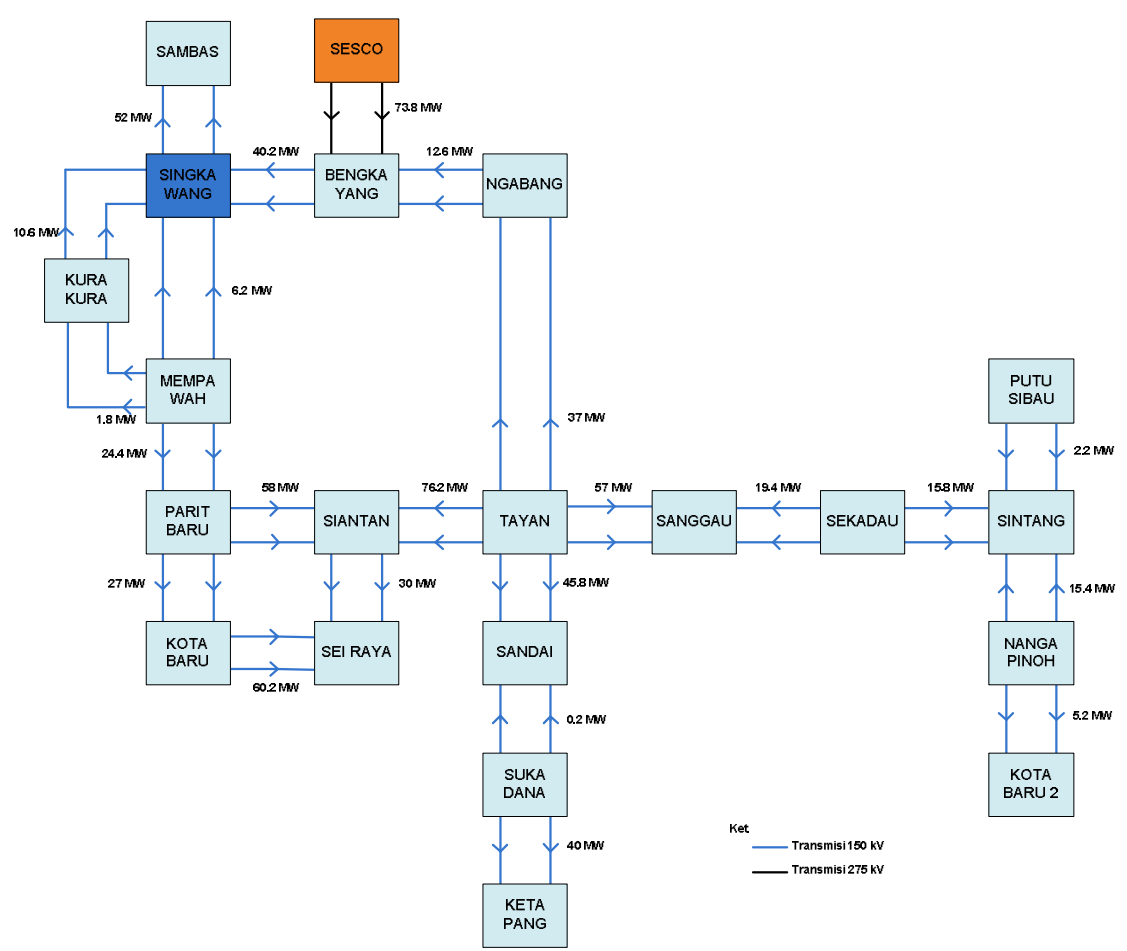

\section{Gambar 6. Aliran daya Kalbar tahun 2031 setelah daya PLTN disalurkan melalui GI Singkawang.}

Gambar 6 menunjukkan aliran daya Kalbar tahun 2031 setelah daya PLTN disalurkan melalui GI Singkawang. Penyaluran daya PLTN melalui GI Singkawang menyebabkan impor SESCO turun menjadi 73,8 MW. GI Sambas yang sebelumnya membutuhkan suplai daya dari GI lain menjadi surplus daya dengan adanya penyambungan daya PLTN dan memasok daya ke GI lainnya.

Dari ketiga kondisi tersebut menunjukkan kondisi aliran daya yang berbeda-beda. Hal itu sesuai dengan hasil penelitian sebelumnya yang menyebutkan aliran daya sangat dipengaruhi oleh parameter saluran dan parameter pembangkit seperti: induktansi, impedansi, kapasitas saluran, daya yang disalurkan, dan kelembaman pembangkit ${ }^{[23-25]}$. Akan tetapi, menunjukkan pola yang sama yaitu mengurangi impor Sesco dan GI yang menjadi lokasi penyaluran PLTN akan menjadi GI yang surplus listrik.

\section{KESIMPULAN}

Analisis aliran daya di sistem kelistrikan Kalbar menunjukkan bahwa hingga tahun 2031, jika pemerintah tidak membuat kebijakan pembangunan pembangkit skala besar, Kalbar akan tetap mengalami kekurangan energi listrik. Lokasi penyaluran daya PLTN yang optimum ke dalam sistem Kalbar dengan faktor kapasitas di atas 80\%, ada 3 kandidat GI, yaitu GI Mempawah, Singkawang dan Sambas. Lokasi paling optimum berada di GI Mempawah dengan faktor kapasitas 83,5\%. Letak ketiga GI ini sejalan dengan salah satu syarat untuk pembangunan PLTN, yaitu tersedianya sumber air pendingin karena lokasi GI tersebut di pinggir pantai. 


\section{UCAPAN TERIMAKASIH}

Penulis mengucapkan terimakasih kepada PT. PLN (Persero) wilayah Kalimantan Barat yang telah membantu dalam penelitian ini.

\section{DAFTAR PUSTAKA}

[1]. PT. PLN (PERSERO), “Rencana Usaha Penyediaan Tenaga Listrik PT. PLN (Persero) 2013- 2022", PT. PLN (Persero), Jakarta, 2013.

[2]. ARSYAD, M. I, "Analisis Krisis Energi Listrik di Kalbar", Jurnal ELKHA Vol. 1 No. 4 Hal. 37 - 44, 2009.

[3]. PKSEN, BATAN, “Indonesia Nuclear Energy Outlook (INEO)”, Pusat Kajian Sistem Energi Nuklir, BATAN, 2014.

[4]. DESDM, "Blue Print Pengelolaan Energi Nasional 2006-2025", Departemen Energi dan Sumber Daya Mineral (DESDM), Jakarta, 2006.

[5]. DHARAMJIT, dan D. K TANTI, "Load Flow Analysis on IEEE 30 Bus System”, Int. Journal of Scientific and Research Publications, Volume 2, Issue 11 pp. 1-6, 2012.

[6]. G. RECHBERGER dkk, "Systematical Determination of Load Flow Cases for Power System Planning", Bucharest Power Tech Conference, Romania, 2009.

[7]. EMMY HOSEA dan YUSAK TANOTO, "Perbandingan Analisa Aliran Daya dengan Menggunakan Metode Algoritma Genetika dan Metode Newton Raphson", Jurnal teknik elektro Vol 4, No. 2, hal. 63-69, Universitas Kristen Petra, 2004.

[8]. WILLIAM AR dkk, "A Radial Scan Method of Power Flow Analysis for Distribution Systems", North American Power Symposium, 2007.

[9]. ADRIANTI dan SILVIA IRIANI, "Studi Aliran Daya Tiga Fasa untuk Sistem Distribusi dengan Metode Pendekatan Langsung", Jurnal TeknikA, No. 29 Vol.2 Thn. XV, hal. 60-66, Universitas Andalas, 2008.

[10]. WITCHAYA, P., et.al., "Blackout Prevention Plan-The Stability, Realibility and Security Enhancement in Thailand Power Grid", Transmission and distribution conference and exhibition: Asia and Pacific, China, 2005.

[11]. NURHANI AMIN, "Perbandingan Metode Gauss-Siedel dan Metode NewtonRaphson dalam Solusi Aliran Daya", Jurnal SMARTek, Vol. 9 No. 3, Hal. 212-222, 2011.

[12]. NAZIA MEHNAZ dkk, "Load Flow Analysis And Abnormality Removal Of Bangladesh Power System Using Software Cyme Psaf", Intelligent Systems Modelling \& Simulation (ISMS), 4th International Conference on, 29-31 Jan. 2013, pp. $384-388$, 2013.

[13]. HADI SAADAT, "Power System Analysis", WCB/McGraw-Hill, Singapore, 1999.

[14]. WIKU LW dan RIZKI FSB, "Studi Pengembangan Kelistrikan Kalimantan Barat dengan Opsi Nuklir Berdaya Kecil dan Menengah", Prosiding Seminar Nasional Teknologi Energi Nuklir, hal. 87-96, 2014.

[15]. CITRA C. dan IWA GARNIWA, “Optimalisasi Penyaluran Daya PLTN di Pulau Bangka untuk Sistem Kelistrikan Sumatera", Jurnal Pengembangan Energi Nuklir, Vol 14, No. 1, hal. 1-10, BATAN, 2012.

[16]. CLARKE, MICHAEL, "Power Generation Systems; Matching Capacity, Load and System Requirements for Cleaner, Adequate, Secure, Reliable and Affordable Energy Supply", Asian Journal on Energy and Environment 10(04) pp. 194-200, 2009.

[17]. KAPLAN, STAN, “Power Plants: Characteristics and Costs”, CRS Report for Congress Orde Code RL34746, 2008. 
[18]. SOVACOOL, BENJAMIN K, "The Interminttency of Wind, Solar, and Renewable Electricity Generators: Technical Barrier or Rhetorical Excuse?", Journal Utilities Policy Elsevier 17 pp. 288-296, 2009.

[19]. PRASETYO, G. E., dkk., “Studi Tentang Indeks Keandalan Pembangkit Tenaga Listrik Wilayah Jawa Tengah dan Daerah Istimewa Yogyakarta", Makalah Seminar Tugas Akhir, Teknik Elektro, Universitas Diponegoro, 2011.

[20]. SHINWARI, M., F., Et al., “Optimization Model using WASP-IV for Pakistan's Power Plants Generation Expansion Plan", IOSR Journal of Electrical and Electronics Engineering Vol. 3 Issue 2 pp. 39, 2012.

[21]. RAMLI, A. T., Et al., "Alternative Energy in Malaysia Beyond 2020-The Need for Nuclear Power", J. Progress in Nuclear Science and Technology Vol. 3 pp. 164-167, 2012.

[22]. DAVIS, L. W., and WOLFRAM, C., "Deregulation, Consolidation, and Efficiency: Evidence from U.S. Nuclear Power", American Economic Journal: Applied Economics 4(4) pp. 194-225, 2012.

[23]. SIDDIQ B. M., dkk, “Optimasi Parameter Interline Power Flow Controller (IPFC) Menggunakan Imperialist Competitive Algorithm (ICA)", Jurnal Teknik ITS Vol. 1 No.1 hal. B-32 - B-37, 2012.

[24]. SANTOSO, S., "Optimasi pada Sistem Daya Listrik", Magistra No. 75 Th. XXIII hal. 51-61, 2011.

[25]. WEKING, A. I., "Pengembangan Analisis Aliran Daya dengan Memperhitungkan Pengaruh Kualitas Energi Listrik", Jurnal Teknologi Elektro Vol. 8 No. 1 hal. 97-105, Universitas Udayana, 2009. 